Celso Ribeiro Bastos, doutor em direito, professor de direito constitucional na Pontífica Universidade Católica de São Paulo-PUC.

1. Sobre esse tópico é particularmente feliz a expressão de João Augusto Filho: "A teoria jurídica moderna vem demonstrando a falácia de se procurarem definições jurídicas dotadas de validade universal. Essa tendência para atingir-se a 'essência' dos conceitos jurídicos, como se estes fossem arquétipos platônicos, eternos e universais, o empenho em construir-se a teoria jurídica sob a forma de uma pirâmide de conceitos científicos, a busca de definições jurídicas essencialistas, tudo isso já foi suficientemente profligado como tentativa inútil e vã" (trabalho apresentado na cadeira de direito constitucional II, sob nossa responsabilidade, do curso de mestrado da Pontificia Universidade Católica - PUCSPI.

\title{
A Tutela dos interesses difusos no direito constitucional brasileiro
}

Ao lado das clássicas noções de interesse público, interesse privado e interesse coletivo, a doutrina assistiu ultimamente ao surgimento de mais uma noção, qual seja, a de interesse difuso. Embora já tenha merecido essa novel categoria jurídica sérios e alentados estudos, sobretudo na ciência jurídica alienígena, um problema permanece para sua exata conceituação. Ė que às dificuldades inerentes ao saber-se em que consiste o qualificativo difuso, somam-se aos de precisar o próprio conceito de interesse. Na linguagem comum a palavra interesse designa ordinariamente a pretensão do indivíduo a determinado bem da vida. Em direito, contudo, o referido termo ganha significações várias, desdobrando-se em diversas acepç̃es, conforme esteja ele associado a este ou àquele campo do universo jurídico. Examinaremos rapidamente cada uma dessas significações. De logo, cumpre registrar, no entanto, que não nos preocupa desvendar um conceito universal de interesse, desvinculado das realidades sobre que se aplica. Cremos que essa preocupação essencialista está hoje superada em direito ${ }^{1}$.

De outra parte, a correlação entre 'interesse' e 'necessidade' é responsável em boa parte pela confusão que, por vezes, é feita entre 'interesse jurídico' e 'interesse material'. Este tem relação com os aspectos psicológicos, econômicos, culturais, etc., da realidade humana, enquanto que o interesse jurídico só considera aqueles ângulos de conveniência que reputou juridicamente relevantes. Ambos conceitos não se sobrepõem, portanto. O interesse de direito é apenas um campo restrito traçado dentro da área maior dos interesses humanos em geral. É forçoso, reconhecer, no entanto, que o interesse juridicamente relevante pressupõe o interesse material, ao menos em caráter genérico. O interesse pela vida em si não fica infirmado pelo fato de o suicida não estar dele possuído. A vida, continua, não obstante a existência daqueles que atentam contra ela, a ser o bem supremo. Vem a propósito lembrar a lição de Emíleo Betti ao 
2. Apud Giorgio Recchia, Considerazioni sulla tutela degli interessi deffusi nella constituzione, p. 32 , nota 14 . profligar a tendência em considerar-se o interesse como uma realidade psicológica, com o conseqüente desprezo da normativa, ao observar que, segundo a primeira é correta "a identificação de interesse com necessidade e desejo", o que permite individuar os interesses "fora do direito", "mas problema inteiramente diverso é a determinação do 'interesse' relevante no âmbito do ordenamento jurídico, enquanto meritório de tutela" 2 .

Na teoria do direito civil, o interesse surge como a outra face do direito subjetivo, ou seja, como o interesse material ínsito neste. Por exemplo, na compra e venda, teríamos do lado do adquirente, o interesse ao gozo da coisa e, sob o ângulo do alienante, o interesse ao recebimento do preço. Esses interesses materiais somente assumem relevância jurídica, convertendo-se em interesses jurídicos, porque tutelados pelo direito ou, em outras palavras, porque erigidos em núcleos de direitos subjetivos.

Dessa ótica, interesse jurídico e direito subjetivo se confundem. Se este último, na consagrada formulação de lhering, não passa do "interesse juridicamente protegido", ou, segundo Coviello, "o poder de agir para satisfação dos próprios interesses, garantido pelo Estado", tais definições não conseguem escapar à circularidade, o que demonstra ser inviável dissociar interesse jurídico e direito subjetivo na civilística européia clássica. Mesmo na moderna teoria, apesar da dura crítica kelseniana, o conceito de direito subjetivo continua a desempenhar um papel importante.

A noção de 'interesse legítimo' não é uma construção do direito brasileiro. Seu desenvolvimento deu-se na doutrina italiana e francesa, tendo em vista peculiaridades desses sistemas jurídicos, no que diz respeito à forma por que neles se dá a distribuição da justiça ou o exercício da jurisdição. Na Europa, de um modo geral, prevaleceu a tendência em dividir a competência jurisdicional entre órgãos do Poder Executivo e do Judiciário. Para a divisão entre estes poderes, das atribuições judicantes, fez-se necessário criar, ao lado do direito subjetivo, o conceito de 'interesse legítimo'. Sobre esse ponto, transcrevemos o seguinte excerto de João Augusto Filho, sempre impecável: "Nesses sistemas de dupla jurisdição, compete ao Poder Judiciário dirimir as controvérsias do particular com a administração, quando estas versem sobre direitos subjetivos, enquanto as questões referentes a lesões sofridas pelos individuos em seus 'interesses legitimos', em decorrência de atos da Administração Pública, são confiadas à decisão dos tribunais administrativos. Somente em algumas hipóteses legalmente predeterminadas, é que os tribunais administrativos são também dotados de competência para decidir certas questões atinentes a direitos subjetivos invocados por particulares em face da Administração Pública.

Há, portanto, entre o direito processual brasileiro e o continental-europeu, uma nítida diferença quanto às posições legitimantes. No direito brasileiro, a legitimatio ad causam da parte se reporta sempre a um direito subjetivo, que realmente existe ou pelo menos assume a aparência de existir, cuja lesão, ameaça ou estado de incerteza objetiva, deverão servir de fundamento para invocar-se a atuação do Judiciário. 
3. Obra citada.

4. Comentários ao Código de Processo Civil, vol. I, tomo I, p. 38 , Forense, 1 ed. $2^{\mathrm{a}}$ tiragem. 1977.
5. Código de Processo Civil comentado, vol. I, p. 222, Ed. Revista dos Tribunais.

6. Chiovenda definiu o interesse de agir nos seguintes termos: "L interesse ad agire consiste in questo, che senza l'intervento degliorganigiurisdizionalil'attore soffrirebbe un danno". Apud Antonio Nasi, Enciclopédia del dirftto, vol. XXII, p. 35, nota b, Giuffrè Editore, 1972.
Já no direito continental-europeu, surgem duas posições legitimantes distintas, uma delas referida a um direito subjetivo e a outra a um'interesse legítimo'. Essas duas posições legitimantes constituem o critério básico para a repartição de competências entre os órgãos judicantes do Poder Judiciário e os tribunais administrativos $^{\prime \prime}$.

A noção de interesse, legítimo, outrossim, não apresenta qualquer utilidade para a superação da dicotomia interesse público e interesse privado, eis que se apresenta umbilicalmente presa a este último. À moda do que passa com o direito subjetivo, o interesse legítimo também ostenta, em seu núcleo, um interesse individual, a que o direito emprestou relevânciajurídica.

Ao examinar-se o conceito de 'interesse de agir', no âmbito do Processo Civil, ver-se-á que ele reproduz, de certo modo, a própria origem da processualística. Tal exame nos faz lembrar que a teoria processual surgiu no seio da teoria do direito civil. Essas raízes ainda estão à mostra, não obstante os grandes avanços da primeira, sobretudo a partir da segunda metade do século passado.

A essa estreita ligação não foi estranho o liberalismo do século XIX, que considerou o próprio direito de ação como um mero reflexo do direito subjetivo, o que levou Celso Agrícola Barbi a afirmar: "Nessa fase não se considerava que a ação fosse um direito distinto daquele direito subjetivo que ela visava proteger. Direito subjetivo material e ação eram um único direito: seriam o verso e o reverso de uma medalha. Em linguagem poética, sustentou-se que a acão é o mesmo direito subjetivo que, violado, se arma para a guerra" ${ }^{\prime 4}$.

Ainda que atualmente já se tenha firmado o caráter autônomo de direito de ação, ainda não se superou a associação historicamento estabelecida entre o interesse de agir e o interesse como núcleo de um direito subjetivo.

O eminente Arruda Alvim, referindo-se genericamente aos interesses jurídicos, especifica-os em 'interesses primários' e 'interesses secundários', elucidando: "O interesse primário é aquele diretamente incidente sobre a pretensão do direito material, ou seja, o que liga o indivíduo a determinado bem da vida. Já o secundário decorre da impossibilidade de utilização normal pelo indivíduo daquele determinado bem da vida"

O interesse secundário nada mais seria do que a utilidade propiciada pela via jurisdicional como meio assecuratório do direito primário, vale dizer, da própria pretensão de direito material ${ }^{6}$.

O que, de tudo, se extrai é que a noção de direito subjetivo continua presente, quer na teoria do direito civil, quer na do processual. A esta exaltação da noção em referência, não foi estranha a própria codificação levada a cabo no século XIX e impregnada de individualismo.

Para o desentranhamento de uma noção autônoma de interesses difusos, entretanto, essa conexão entre interesse de agir e direito subjetivo remanesce como um obstáculo a ser transposto, se é que se queira efetivamente levar a bom cabo a empreitada. 
7. Reportando-se a Theodor Viehweg, Tércio Ferraz Sampaio lembra, para salientar o caráter problemático da teoria jurídica, que "noções-chaves como interesse público... guardam um sentido vago", (Prefácio à tradução brasileira da obra Tópica e jurisprudência, de Viehweg, Departamento de Imprensa Nacional).

8. Intervenção do Ministério Público nas causas a que se refere o art. 82, item III, do Código de Pro. cesso Civil, Revista Brasileira de Direito Processual, vol. 18, p. 14, Forense.
É que a característica primordial do interesse difuso é a sua não-coincidência com o interesse de uma determinada pessoa. Ele abrange, na verdade, toda uma categoria de indivíduos unificados por possuirem um denominador fático qualquer em comum.

A tutela desses interesses difusos está na estrita dependência da dissociação que se venha a fazer entre o interesse de agir e o direito subjetivo. Em outras palavras, cumpre reconhecer o interesse de agir mesmo em situações onde não esteja presente o clássico direito subjetivo lesado, que exige um nível de concreção e individualização que as modernas formas de agravo a direitos, por serem abstratas e coletivas, não possuem.

A expressão 'interesse público' vem tisnada por um alto grau de indeterminação, nos diversos ramos do direito em que ela é utilizada: processual, administrativo ou constitucional?

É verdade que o teor dessa vaguidade acentou-se com o advento do Estado social de direito, porquanto o Estado de direito clássico, ao arvorar-se em guardião da ordem e da propriedade, chegou a determinar com certa nitidez o âmbito dos interesses públicos.

Tarnbém os processualistas afirmam que a expressão 'interesse público' exsurge como de significação vaga. Discorrendo sobre a interpretação do art. 82, item III, do Código de Processo Civil vigente, J. J. Calmon de Passos, invocando Alessandro Pizzorusso, observa que o signficado de interesse público "tende a confundir-se com o de muitas outras expressões semelhantes, entre estas relacionando exemplificativamente: interesse geral, interesse da lei, interesse coletivo...". E conclui: "Todas essas noções têm uma base comum, mas as indagacõos já realizadas e os esforços empreendidos pelos estudiosos têm sido de escassíssimos resultados e de quase nenhuma utilidade, quando buscam definir o interesse público mediante uma fórmula descritiva resultante de um processo de generalizaç̃̃o"8.

De outra parte, a dicotomia interesse público/interese privado, exacerbada pela ideologia do liberalismo jurídico, contribuiu para impedir que se destacasse, entre o interesse público próprio e o interesse particular, uma categoria intermediária constituída pelo interesse coletivo. Este, pouco tem a ver com o direito individual do trabalho. Somente o direito coletivo do trabalho, por vezes intitulado de direito sindical, é que constitui setor importante, mas não o úni$\mathrm{co}$, do direito social ou coletivo. Afirma João Augusto Filho: "Em sua maioria, os autores que, na ampla moldura do direito, procuram destacar o direito coletivo não rompem declaradamente com a dicotomia direito público/direito privado. Argumentam que o direito coletivo ou social não chegaria a assumir feições de categoria autônoma, de tertium genus, mas apresentaria tão-só aspectos mistos, distribuídos entre o direito privado e o direito público".

Aliás, entendem esses autores que, tratando-se de interesses coletivos, pouco importa que as respectivas relações sejam reguladas segundo as formas de direito privado, como afirma Cesarini Sforza (Preliminari sul dirftto collettivo, p. 114): "Não obstante o uso dessas formas, as relações se configurarão como coletivas, isto é, 
como fontes de direitos e deveres diferentes dos de direito privado e naturalmente diversos também dos direitos e deveres de direito público".

Não se pode deixar de reconhecer, ao examinar os interesses coletivos que, embora eles não se confundam com os interesses difusos, sua identificação constituiu-se num passo enorme na conceituação destes últimos. É que os interesses coletivos dizem respeito ao homem socialmente vinculado e não ao homem isoladamente considerado. Colhem, pois, o homem não como simples pessoa física tomada à parte, mas sim como membro de grupos autônomos e juridicamente definidos, tais como o associado de um sindicato, o membro de sua família, o profissional vinculado a uma corporação, o acionista de uma grande sociedade anônima, o condômino de um edifício de apartamentos.

Interesses coletivos seriam, pois, os interesses afetos a vários sujeitos não considerąos individualmente, mas sim por sua qualidade de membros de comunidades menores ou grupos intercalares, situados entre o indivíduo e o Estado.

Há autores, como Giorgio Recchia por exemplo, que usam a expressão interesses coletivos como sinônima de interesses difusos. Entendemos, pelo contrário, que cumpre distinguir interesses coletivos de interesses difusos. Nos interesses coletivos, há um vínculo jurídico básico, uma geral affectio societatis, que une todos os indivíduos, como as relações de parentesco no grupo familiar, o título de acionista na sociedade anônima, a qualidade de integrante de determinada categoria profissional, além do título jurídico de sócio no associado de um sindicato, o título de bacharel em direito e a qualidade de membro da corporação profissional, no caso de um advogado inscrito na O.A.B., etc.

Ao contrário, no caso dos denominados interesses difusos, não se nota qualquer vínculo jurídico congregador dos titulares de tais interesses, que praticamente se baseiam numa identidade de situações de fato. Quando nos referimos aos interesses difusos dos usuários de automóveis, por exemplo, abarcamos uma indefinida massa de indivíduos das mais variadas situações, esparsos por todo o País, sem qualquer especial característica jurídica homogênea, que apenas praticaram, aos milhares ou milhões, um mesmo ato jurídico instantâneo - a compra de um veículo.

Com efeito, parece residir aqui a nota tipificadora dos interesses difusos. Caracterizam-se eles, na verdade, pela natureza extensiva, disseminada ou difusa das lesões a que estão sujeitos. Os efeitos danosos das lesões aos interesses difusos apresentam-se amplos e não circunscritos, num fenômeno de propagação altamente centrífuga.

A sociedade hodierna, de produção em massa, de consumo em massa, de ampla intervenção estatal, engendrou também novas e imprevistas modalidades de lesões portadoras de danos coletivos. Difusa ou disseminada é a conseqüência danosa da lesão que, por exemplo, no caso de um produto fabricado em série, pode atingir milhares de indivíduos, dispersos em vários locais. Mesmo na hipó- 
tese de interesses difusos ligados a uma comunidade mais circunscrita (por exemplo, munícipes de determinado núcleo urbano), os efeitos danosos da lesão afetam série aberta de pessoas.

Os interesses difusos constituem, pois, decorrência da sociedade tecnológica, de produção e consumo massificados, com a participação de empreendimentos públicos ou privados de avultadas proporções, dando lugar a uma mutação veloz e constante, em cujo bojo ocorrem lesões de um novo perfil, marcadas pelo grande número dos atingidos assim como pela sua indeterminação.

Por outro lado, o propósito estatal de elevar a capacidade produtiva, ao ser implementado pelo método mais expedito e econômico, muitas vezes sem compatibilização com os valores jurídicos igualmente relevantes, conflitará com outros interesses - como os de defesa do ambiente natural, combate à poluição, preservação de parques ou reservas naturais, controle de sanidade de alimentos produzidos em grande escala com utilização de substâncias tóxicas, controle de qualidade de produtos em série etc.

Dentro desse quadro multifário de numerosos interesses colidentes, a busca de resultados imediatos pela via mais econômica poderá culminar sacrificando certos interesses coletivos ou públicos, ao se privilegiarem outros interesses igualmente públicos, gerando frustrações e dissenso em amplos segmentos da sociedade, não propensos a endossar um desenvolvimento a qualquer preço.

Os interesses difusos podem, por vezes, opor-se a outros interesses também difusos e não necessariamente a interesses coletivos ou públicos. Veja-se o caso, por exemplo, da construção de um aeroporto para uma cidade. Em regra não se discute a conveniência em si da implantação da estação aeroviária. Esta concordância quanto ao fim não exclui, contudo, a possibilidade de os agrupamentos humanos circundantes à área escolhida procurarem deslocá-la para outro ponto, passando destarte a conflitar com os interesses dos habitantes da nova região cogitada. E assim sucessivamente. Outras vezes, ataca-se a obra em si mesma, não sendo relevante o local que a acolherá. É o que se dá com a rejeição pelos grupos ecologistas da criação de usinas atômicas. Estas são tidas em si mesmas como nefastas, não importando onde venham a ser construídas.

De outra parte, a ampla conflituosidade ínsita em certas decisões empresariais ou ainda em determinadas opções políticas - nas quais se engajam unidos, ou mesmo se consociam, o setor público e segmentos do setor econômico privado - constitui característica importante dos interesses difusos, conotação específica destes e desconhecida dos tradicionais conflitos de interesse de âmbito dual.

Dessa forma, pode-se antever em futuro próximo um novo tipo de processo civil, de natureza coletiva, no qual não mais assistiremos aos clássicos dualismos autor versus réu ou indivíduo versus autoridade pública, mas sim ao alinhamento no processo de várias partes coletivas, numa multiplicidade de posições concorrentes ou conflitantes. 
Recentes episódios, no Brasil e no estrangeiro, como os conflitos surgidos da localização, neste ou naquele sítio, de um aeroporto (aeroporto de Narita, no Japão, o supersônico de São Paulo, o novo aeroporto de Belo Horizonte), ou ainda a forte oposição de segmentos sociais às atividades predatórias do meio ambiente (episódio da mata do Jambreiro em Belo Horizonte, ameaçada de destruição por uma empresa transportadora de minério de ferro) constituem prenúncios eloqüentes do que deverá ser o processo judicial coletivo do futuro.

Os conflitos respeitantes aos interesses difusos não colocam em posições antagônicas apenas indivíduo, contra indivíduo, ou indivíduo contra autoridade pública, como sói acontecer no processo tradicional; não envolvem tão-só sindicatos de empregados contra sindicatos patronais, como ocorre no processo coletivo trabalhista, mas sim apresentam caráter vagamente circunscrito, podendo abranger o Estado, empresas, segmentos sociais ou mesmo comunidades inteiras.

É a complexidade da sociedade de produção e consumo em massa, a forçar o surgimento de novas instâncias de afirmação do coletivo, antes inéditas, a fazer eclodir seus múltiplos antagonismos, não abarcáveis no clássico dualismo autor versus réu.

Os interesses difusos são titularizados por numerosos indivíduos que, ou compõem grupos mal circunscritos, ou nem mesmo chegam a constituir verdadeiros grupos, já que seus titulares muitas vezes disseminam-se entre as várias camadas sociais, em âmbitos diversos e não circunscritos. Em conseqüência disso, o conjunto dos titulares dos interesses difusos apresenta, como afirma o eminente professor Barbosa Moreira, contornos fluidos, móveis, esbatidos, de difícil e quase impossível individualização. Isto demonstra a inerência dos interesses difusos à sociedade de massas, porque o próprio conceito de massa encerra a denotação de algo amorfo.

Ao focalizar as associações surgidas com o objetivo da tutela dos interesses difusos, mais uma vez se faz oportuno João Augusto Filho, averbando: "Mesmo quando os titulares dos interesses difusos se agrupam em associações para melhor defendê-los (associações de proteção ao consumidor, defesa do meio ambiente, por exemplo), que aliás hoje brotam e vicejam às centenas, tais associações se apresentam como organizações abertas, altamente informais, reunindo componentes de diversos estratos da sociedade, dispensando requisitos de prévia qualificação jurídica ou desconhecendo distinções de classe. Tratam-se de agrupamentos que adquirem personalidade jurídica como requisito necessário à sua existência, mas permanecem bastante informais, por não terem sido objeto de disciplina normativa especial, de estruturação legal rígida ou de estrita tipificação jurídica, ao contrário dos organismos coletivos já tradicionais, como a família, o sindicato, a sociedade anônima, que constituem instituições jurídicas de modelo bem estruturado, constante de um plexo de normas legais".

Por isso, o momento associativo, insuprível nos interesses coletivos tradicionais, não assume igual relevância no tocante aos inte- 
9. Conselho Administrativo de Defesa Econômica - CADE, órgão criado através da Lei $n^{0}$ 4.137 de 10 de setembro de 1962, vinculado à presidência do Conselho de Ministros, tem como incumbência a apuração e repressão dos abusos do poder econômico.

10. Superintendência Nacional de Abastecimento - SUNAB, autarquia federal, criada em 26 de setembro de 1962, através da Lei Delegada n? 5, ligada ao Ministério da Agricultura. Em 27 de dezembro de 1979 foi vinculada à Secretaria de Planejamento da Presidência da República - SEPLAN, através do Decreto $n$ ? 84.344. Tem como objetivo dar execução à política nacional de abastecimento, formulada pelo Conselho Nacional de Abastecimento - CONAB, no tocante a alimentos in natura e industrializados, produtos vegetais e animais, assim como bens e serviços relativos às atividades da agropecuária e da pesca.

11. Comissão de Valores Mobiliários - C.V.M., entidade autárquica vinculada ao Ministério da Fazenda, criada através da Lei n? 6.385, de 7 de dezembro de 1976; tem como principais funções a regulação e a fiscalização das atividades do mercado de capitais, de acordo com a Portaria do Ministro da Fazenda de $\mathrm{n}$ ? 327, de 11 de julho de 1977. resses difusos. Podem estes ser afirmados independentemente das associações que os corporifiquem, como ocorre nas class actions do direito norte-americano, nas quais o indivíduo isolado ingressa em juízo na defesa de toda uma classe, para obter sentença de eficácia extensiva a todos os membros da categoria envolvida.

A Constituição do Brasil é menos explícita ou incisiva que as congêneres mais recentes, no tocante aos interesses difusos. Mesmo assim, vários desses interesses assumiram, entre nós, relevância constitucional, como se passará a ver.

Não existe menção à tutela dos interesses do consumidor na Constituição Federal. Isto não significa, contudo, que tais interesses não tenham ainda assumido, entre nós, relevância constitucional. Esta deduz-se da disposição do inciso $\mathrm{V}$ do art 160 da Constituição, que reprime o abuso do poder econômico, caracterizado este pelo domínio dos mercados, a eliminação da concorrência e o aumento arbitrário dos lucros.

Quais são os fins visados por essa norma? A resposta está no próprio caput do art. 160: o desenvolvimento nacional e a justiça social. Se um dos objetivos visados é a justiça social, segue-se que a proteção dos consumidores se insere no âmago dos fins sociais a que se dirige o mandamento constitucional em foco. Ademais, é exatamente o consumidor que deve ser defendido do aumento arbitrário dos lucros referido no inciso $V$ do art. 160 . Assim, embora esta norma acarrete também a proteção do interesse empresarial, é de concluir-se que seu objetivo maior é proteger o interesse dos consumidores, e não só apenas destes, mas também dos milhões de aplicadores em fundos de investimentos, bolsa de valores, etc.

Como nossa abordagem se restringe ao plano constitucional, abster-nos-emos de tecer comentários sobre a legislação ordinária que cogita da repressão ao abuso do poder econômico e sobre as atribuições de órgãos administrativos como o $\operatorname{CADE}^{9}$, a SUNAB ${ }^{10} \mathrm{e}$ a C.V.M. ${ }^{11}$.

$\mathrm{Na}$ Constituição Federa/ todavia, surgem ainda outros interesses difusos, que assumiram assim o mais alto grau de relevância jurídica e que são assim expressamente previstos: assistência do poder público à maternidade, à infância e à adolescência, bem como à educação dos excepcionais (art. 175, § 4.); educação como direito de todos e dever do Estado, inspirada nos ideais de liberdade e solidariedade humana (caput do art. 176); ensino primário gratuito nos estabelecimentos oficiais e ensino público gratuito nos níveis médio e superior, sob algumas condições ( $\$ 3^{\circ}$. do art. 176); incentivo do Poder Público à pesquisa e ao ensino científico e tecnológico (parágrafo único do art. 179); proteção pelo Poder Público dos documentos, obras e locais de valor histórico ou artístico, dos monumentos e das paisagens naturais notáveis, bem como das jazidas arqueológicas (parágrafo único do art. 180); amparo público à cultura (art. 180, caput); função social da propriedade (item III do art. 160); higiene e segurança do trabalho, assistência sanitária, hospitalar e médica aos trabalhadores, colônias de férias, clínicas de repouso (art. 165); meIhoria da condição social e econômica dos deficientes, mediante 
educação especial gratuita, assistência, reabilitação e reinserção na vida econômica do país, proibição de discriminação, etc. (Emenda Constitucional n. 12 , de 17 de outubro de 1978) e, proibição de discriminação por motivo de sexo, raça, trabalho, credo religioso, e convicções políticas (art. 153, § 1\%).

Estudemos agora os meios judiciais de que se pode valer para a proteção dos interesses difusos. Os processualistas que, entre nós, versaram o tema (Barbosa Moreira, Ada Pellegrini Grinover, Waldemar Mariz de Oliveira Junior), são acordes em apontar a ação popular como instrumento apto a tutelar esses interesses.

Um dos óbices à 'efetiva' tutela jurisdicional dos interesses difusos no Brasil é a proibição de pleitear-se direito alheio em nome próprio (art. 6 do Código de Processo Civil). A Ação Popular rompe com esse princípio, mediante a legitimação extraordinária de qualquer cidadão para ingressar em juízo com vistas à tutela não de um interesse estritamente individual, mas sim do interesse público.

Mas, por outro lado, o dispositivo constitucional restringe o alcance da Ação Popular como possível instrumento de tutela dos interesses difusos. E que a Ação Popular visa anular atos lesivos ao patrimônio das entidades públicas. Essa limitação do cabimento da ação popular aos atos lesivos ao patrimônio das entidades públicas coloca, de plano, fora do âmbito de sua atuação numerosos interesses difusos, como, por exemplo, os referentes à proteção do consumidor.

A Lei $0^{\circ}$ 4.717, de 29 de junho de 1965 , em seu art. 1 ? $\S 11^{\circ}$, define como patrimônio público os bens e direitos de valor econômico, artístico, estético ou histórico. Dessa forma, para efeitos de propositura da Ação Popular, o patrimônio não é apenas o conjunto de bens econômicos das entidades públicas, abrangendo ainda os bens irredutíveis a um preciso valor econômico, como os de significado artístico, estético ou histórico.

Esse conceito desmonetizado e amplo de patrimônio possibilita que a Ação Popular seja utilizada na tutela de determinados interesses difusos ligados ao urbanismo, às atividades edílicas à proteção do meio ambiente, à preservação de paisagens naturais notáveis, jazidas arqueológicas e de obras ou locais de valor artístico.

A Ação Direta de Declaração de Inconstitucionalidade, lembra João Augusto Filho, só eventualmente pode configurar instrumento de defesa de interesses difusos. Quanto ao Poder Judiciário, através da sua jurisprudência, poderá ele assumir relevante papel na tutela dos interesses difusos, o que já se vem notando em algumas sentenças que se desviam da estreita vinculação entre interesse próprio, individual e legitimação processual ativa. 
